\title{
Optimal Scale Selection for DEM Based Slope Segmentation in the Loess Plateau
}

\author{
Mingwei Zhao, Fayuan $\mathrm{Li}^{*}$, Guo'an Tang \\ Key Laboratory of Virtual Geographic Environment, Ministry of Education, Nanjing Normal University, Nanjing, China \\ Email: *lifayuan@njnu.edu.cn
}

Received May 9, 2011; revised August 9, 2011; accepted November 7, 2011

\begin{abstract}
Optimal scale selection is the key step of the slope segmentation. Taking three geomorphological units in different parts of the loess as test areas and $5 \mathrm{~m}$-resolution DEMs as original test date, this paper employed the changed ROC-LV (Lucian, 2010) in judging the optimal scales in the slope segmentation process. The experiment results showed that this method is effective in determining the optimal scale in the slope segmentation. The results also showed that the slope segmentation of the different geomorphological units require different optimal scales because the landform complexity is varied. The three test areas require the same scale which could distinguish the small gully because all the test areas have many gullies of the same size, however, when come to distinguish the basins, since the complexity of the three areas is different, the test areas require different scales.
\end{abstract}

Keywords: Optimal Scale; Multiresolution; Slope Segmentation; Loess Plateau

\section{Introduction}

Quantificational analysis of loess terrain is a key subject in the research of the loess plateau [1-7]. Slope is the basic element of geomorphology. Based on slope point of view, Tang et al. (2008) proposed slope spectrum to quantitatively describe loess landform [8], Zhou et al. (2010) discussed the spatial pattern of loess landform based on loess positive and negative terrain [9], and other researches focus on the extracting of loess landform unit, such as gully area, gully bottom area and inter gully area [10]. However, their research cannot properly describe the spatial structure of loess slope. Considering different landform is composed by different slopes, so the study of the spatial structure of loess slope could be a new way to analyze the loess terrain [11].

In order to analyze the loess terrain based on slope, different types of slope should be classified well and truly. Slope classification has long been researched since 1950 's. Hammond (1964) gave a manual way based on contoured map [12]. With the increasing availability of commercial GIS software, Dikau et al. (1991) developed GIS technology to automatic slope classification based on Hammond's method [13]. Philip (1998) put forward an approach to the classification of the slope units using digital data [14]. Dragut and Blaschke (2006) proposed an object-oriented method to carry out the slope segmentation process [15]. This method has been proven to be

\footnotetext{
*Corresponding author.
}

reproducible, readily adaptable for diverse landscapes and datasets. However, the limitation of this method is that it request specify the scale level.

In fact, optimal scale selection is a key issue in the image analysis $[16,17]$. As we known, image segmentation is the first step of image analysis, and it is also the fundamental process of Object-oriented Remote Sensing image classification. Most of the image segmentation methods are based on image characteristic, take given algorithm parameter, usually the parameter is a threshold which can separate the adjacent area, to separate the image into areas of different characteristic, so it is a scale problem in nature [18]. Generally speaking, small scale can generate smaller image area which could show more details, while large scale generate larger image area which could express the objects of unusual. In the process of object-oriented remote sensing image classification, if the scale selected is too large, some small object may be submerged by the larger object; if the scale selected is too small, the segmentation process may generate fragmentation result. So selecting the optimal segmentation scale is the key issue in object-oriented remote sensing image classification. There are many methods of optimal scale selection for image segmentation based on pixel [19-22].

However, traditional pixel-based image segmentation approaches are poorly suited to very high spatial resolution imagery $[23,24]$. Object-based image analysis became prevalent through the realization that image-objects hold more real-world value than pixels alone [25-27]. Though 
the object-based image analysis is becoming increasingly prominent in remote sensing science [28], the optimal scale selection is still dependent on subjective trial-anderror method [29]. Aimed at these problems, Lucian et al. (2010) put a new conception (ROC-LV) which could employed to select optimal scales in the object-based image analysis. Tests on different types of imagery indicated accurate results [30].

This paper applied the ROC-LV to select the optimal scale for the DEM based slope segmentation. Because the datasets tested in Lucian's study is quite different with the datasets used for the slope segmentation, the most distinct difference is that there is no clear boundary among different types of slope. So in this paper some change was made in order to make the method suit to our study. This paper took three geomorphological units in different parts of the loess as test areas and $5 \mathrm{~m}$-resolution DEMs as original test date, used the changed ROC-LV to realize slope segmentation. Experiment results show that though the datasets are rather different with the ordinary imaginary, the changed ROC-LV could still indicated the optimal scales for the slope segmentation based on DEMs.

\section{Methods}

\subsection{Study Area and Data}

Three areas, all located in Shaanxi province, are selected as the test areas (Figure 1). The first area located in Suide County, which is one of the key watersheds of soil and water conservation. The highest elevation above sea is $1115 \mathrm{~m}$ and the lowest elevation is $892 \mathrm{~m}$. The main landform of this area is Loess Hill. Average annual precipitation is $486 \mathrm{~mm}$ and average temperature is $9.7^{\circ} \mathrm{C}$. The second area located in Ganquan County. The highest elevation above sea is $1459 \mathrm{~m}$ and the lowest elevation is $1147 \mathrm{~m}$. the main landform of this area is Loess Ridge. Average annual precipitation is $670 \mathrm{~mm}$ and average temperature is $10.4^{\circ} \mathrm{C}-13.6^{\circ} \mathrm{C}$. The third area located in Yijun County. The highest elevation above sea is $1158 \mathrm{~m}$ and the lowest elevation is $768 \mathrm{~m}$. the main landform of this area is Loess Tableland. Average annual precipitation is $709 \mathrm{~mm}$ and average temperature is $8.9^{\circ} \mathrm{C}$. The locations here belong to the continental monsoon climate. The main vegetation covers are shrubs and grass, severe soil and water loss is the main problems in these areas.

Test dates are the corresponding $5 \mathrm{~m}$-grid resolution

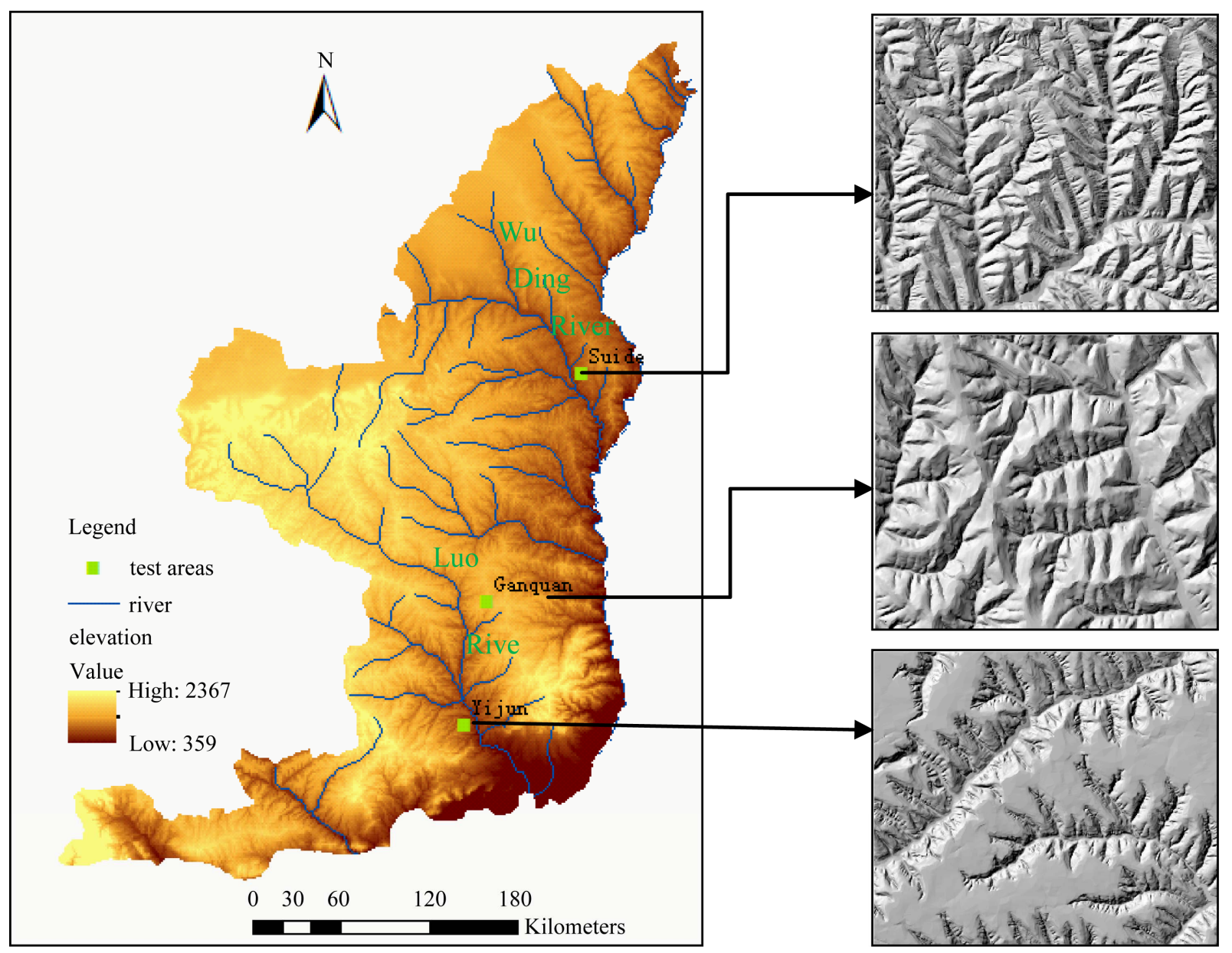

Figure 1. Distribution of the test areas. 
DEMs produced according to the national standard of China.

\subsection{LV and ROC-LV}

The original idea of using local variance to select optimal scale was raised by Woodcock, Strahler and Jupp (1998) [31]. Given the same region's image with different scales, we can find the optimal scale through calculating each image's local variance. The calculation steps are list as follows:

Firstly, set an analysis window on each image, move the window through the entire image and calculate the variance of all the pixel value in the window on each position. Suppose the window is $(2 a+1) \times(2 a+1)$,

$f(i, j)$ is the pixel value of the $(i, j)$ position, then the local variance of the window which take this pixel as the center can calculate by the following formula:

$$
\sigma_{i j}^{2}=\frac{1}{(2 a+1)^{2}} \sum_{k=i-a}^{i+a} \sum_{l=j-a}^{j+a}\left|f(i, j)-u_{i j}\right|^{2}
$$

where $\sigma_{i j}^{2}$ is the local variance. $u_{i j}$ is the mean of the pixel value in the window.

Secondly, calculate the mean of all the local variance of the image, so the mean local variance of the image can be expressed as:

$$
\sigma^{2}=\frac{1}{(L-2 a) \times(M-2 a)} \sum_{i=a+1}^{L-a} \sum_{j=a+1}^{M-a} \sigma_{i j}^{2}
$$

where $\sigma^{2}$ the image's local variance, $L$ is the rows of the image and $M$ is the columns of the image.

Finally, take the images' spatial resolution as abscissa, the mean local variance as the vertical coordinates, and plot the local variance graph. Observe the variance trend of the local variance as the scale become coarser, the scale can select as the optimal scale at which the local variance achieve the peak in the local variance graph.

Kim (2008) made advances toward addressing this issue in the context of OBIA by exploring the relationship between segmentation variance and spatial autocorrelation at different scale parameters to define the optimal object size [32]. The above methods focused on one optimal scale, which is appropriate for simple scene models; however, many environmental problems cannot be handled at a single scale of observation, researchers often have to deal with nested models of a scene. As such, multiscale analysis and representation require more than one suitable scale parameter to account for different levels of organization in landscape structure.

Lucian (2010) calculate the local variance of objects generating through segmentation under different scales, in order to assess the dynamics of the local variance from an object level to another, the author use a measure called rate of change (ROC). Through several experiment analysis, the author found that the peaks in the LV-ROC graph could indicate the object level at which the image can be segmented in the most appropriate manner.

However, the method put forward by Lucian requested too much calculation. On the other hand, it is difficult to select the optimal scales using the local variance based on pixel graph. SO we utilize Lucian's method as reference, define the rate of change in the same way. The difference is our calculation is based on pixel, rather than objects.

$$
\mathrm{ROC}=\frac{L V_{l}-L V_{l-1}}{L V_{l-1}}
$$

where $L V_{l}$ is the local variance at the target level and $L V_{l-1}$ is the local variance at next lower level.

\subsection{Segmentation on eCongnition}

An object-oriented method proposed by Dragut and Blaschke (2006) is adapted to loess slope segmentation [14]. Firstly, several data layers are extracted from Digital Elevation Models (DEM): profile curvature, plan curvature and slope gradient. Secondly, every data layer is taken as a single-band image, and then the three single-band images are combined into a multiband image. Then append a new process in the process tree. Six parameters should be defined: (a) segmentation algorithm, multiresolution segmentation is selected in this paper; (b) Image Object Domain, since the segmentation would be carried out based on the original image, so pixel level is selected; (c) Image Layer weights, we defined the same weight for the three single-band image; (d) Scale parameter, the definition of this parameter is discussed in the next part of the paper; (e) Composition of homogeneity criterion, the parameter shape define the weight that the shape criterion should have when segmenting the image. The higher its value is, the lower the influence of color on the segmentation process. The parameter compactness defines the weight of the compactness criterion. The higher the value, the more compact image objects may be. By lots of experiments, we set the shape as 0.3 and the compactness 0.5 . The entire tests are run on the eCongnition software which is developed by Definiens Company.

\section{Result and Discussions}

The segmentation process requests three layers: slope, plan curvature and profile curvature. In order to make the analysis easy to interpret and make sure the result consistent, the three images were integrated into a syntheticcal layer according to the weights 1,1 , and 1 . The concrete fusion process could be carried out as following:

Firstly, calculate each layer according formula (4) to make the pixel value range from 0 to 1 . This process can 
eliminate the dimensional influence on the different layers.

$$
p_{i j-\text { new }}=\frac{p_{i j}-p_{\text {min }}}{p_{\text {max }}-p_{\text {min }}}
$$

where $p_{i j}$ is the original value of the pixel in the place $(i, j)$, and $p_{i j-\text { new }}$ is the calculated value of the same pixel; $p_{\min }$ is the minimum value and $p_{\max }$ is the maximum of the layer.

Then, carry out raster calculation according to formula (5) to integrate three layers into a synthetical one.

$$
p_{i j-s y n}=\frac{p_{i j-1}+p_{i j-2}+p_{i j-3}}{3}
$$

where $p_{i j-s y n}$ is the value of the pixel in the place $(i, j)$ of the synthetical layer, $p_{i j-1}, p_{i j-2}$, and $p_{i j-3}$ is the value of the pixel in the same place of the three layers.

Haven obtained the single synthetical layer. This paper employed ArcGIS 10.0 to calculate the local variance at different scales. Firstly, use the Block Statistics tool to calculate the local variance under the $3 \times 3$ window, and then change the analysis scale by change the size of the moving window to calculate the new local variance; Repeat the above work until the scale up to some decided value. At last, we obtain the local variance at different scales.

\subsection{LV and ROC-LV Graph}

Utilized the local variance at different scales, one could plot the LV-Scale graph (Figure 2). Figure 2 shows that the local variance increased as the resolution becomes coarser, but the velocity of the increase declines. The local variance tends to become a fixed value when the scale became large enough. These results could be explained as following: when the image's resolution is much smaller than the objects' size, in another word, the resolution is very high, each pixel in the image has high correlation with its neighbor, so the local variance is small; as the objects' size is equivalent to the spatial resolution, the value of each pixel is different with others, so the correlation decrease, leading the local variance increase. In the experiment of this paper, because there are no obvious boundaries among different slopes, so the local variance doesn't mount up to a peak, the local variance increase more slowly as the spatial resolution becomes coarser, finally tends to become a fixed value.

Haven obtained the local variance at different spatial resolution; the local variance-rate of change (LV-ROC) could be calculated according to the formula (3). Furthermore, one could plot the LV-ROC-Scale graph (Figure 2). Be aware that in this paper we removed five points in the front, because comparing with the other values, the five values in the front is too high, so it is difficult to find the jump points when plot them together.
From the Figure 2, it could be found that as the spatial become coarser, the local variance decrease with many jumping points. Because these jumping points could indicate the large change of the local variance under certain spatial resolution, these jumping points likely indicated the optimal segmentation scales.

\subsection{Segmentation Results}

This paper selected three obvious jumping points for each experiment areas, marked with broken line in the LV-ROC graph. For Suide, scales relevant to the jumping points are 40, 90, and 110; for Ganquan, scales relevant to the jumping points are 45,105 and 115; for Yijun, scales relevant to the jumping points are 45,105 and 155 . Carry out the segmentation process under the three scales. The segmentation results are listed in Figure 3. In order to observe the equality of the segmentation, the segmentation results were overlaid on the hillshade of the originnal DEMs.

The segmentation results showed that at the small scale, boundaries of different slopes' could be segmented from the synthetical layer. As the scale became large, the segmentation results became fuzzier, because many similar slopes can't be differentiated; as the scale kept on increasing, the small basins were seemed as a type of slope. So we could conclude that the three segmentation results reflect the objects' boundaries of different levels. Compare the experiment results of the three areas, it could also be found that the first and second optimal scale for the three areas are similar, the reason is that all the test areas have lots of gullies of the same size on the whole. However, since the Yijun area is more flat than Suide area and Ganquan area, so the third optimal scale for the Yijun area is much larger.

\section{Discussion and Conclusions}

Although the production of multiscale representation of spatial entities has been technically enhanced in OBIA through image segmentation, choosing the suitable levels of representation has remained a challenge. Kim et al. (2008) proved that LV graphs indicate the optimal scale parameter for delineating forest stands, but their work focused on a single scale. Although our segmentation process is pixel based, the LV graph doesn't peak or declined, the graphs we obtained followed a relatively smooth variogram shape. While appropriate for detecting a single scale, the LV graph is not suitable for a multiscale approach. So this paper applied Lucian's conception in choosing the optimal scale in the multiresolution segmentation process.

Lucian's work calculated the local variance based on segmentation results, this idea may appropriate for images which contain objects that have obvious boundary. 

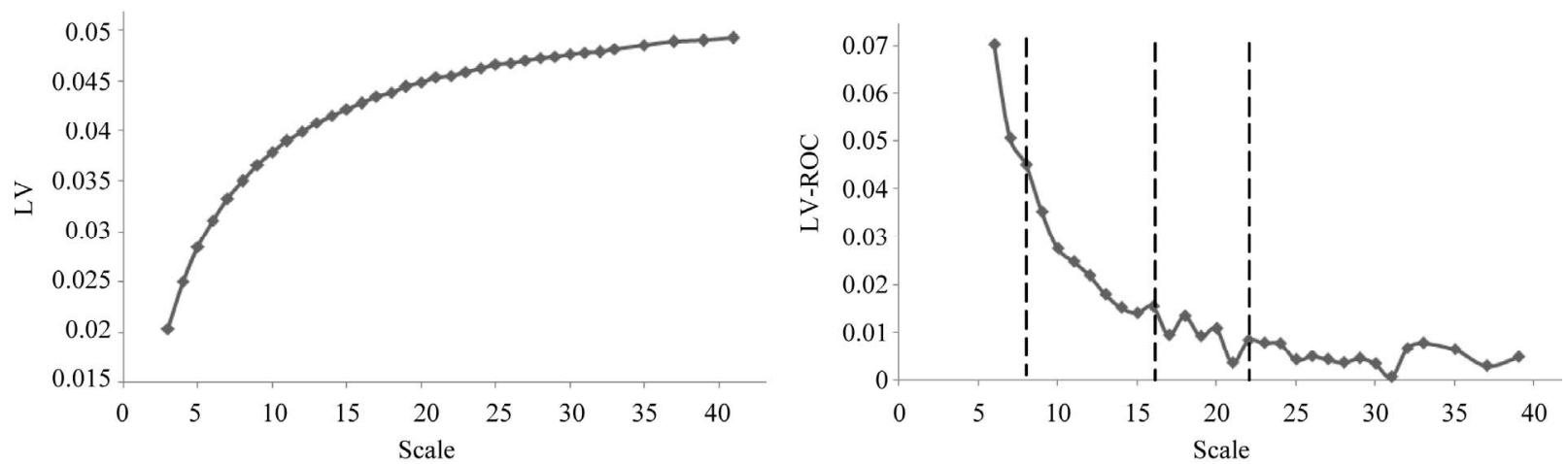

(a)
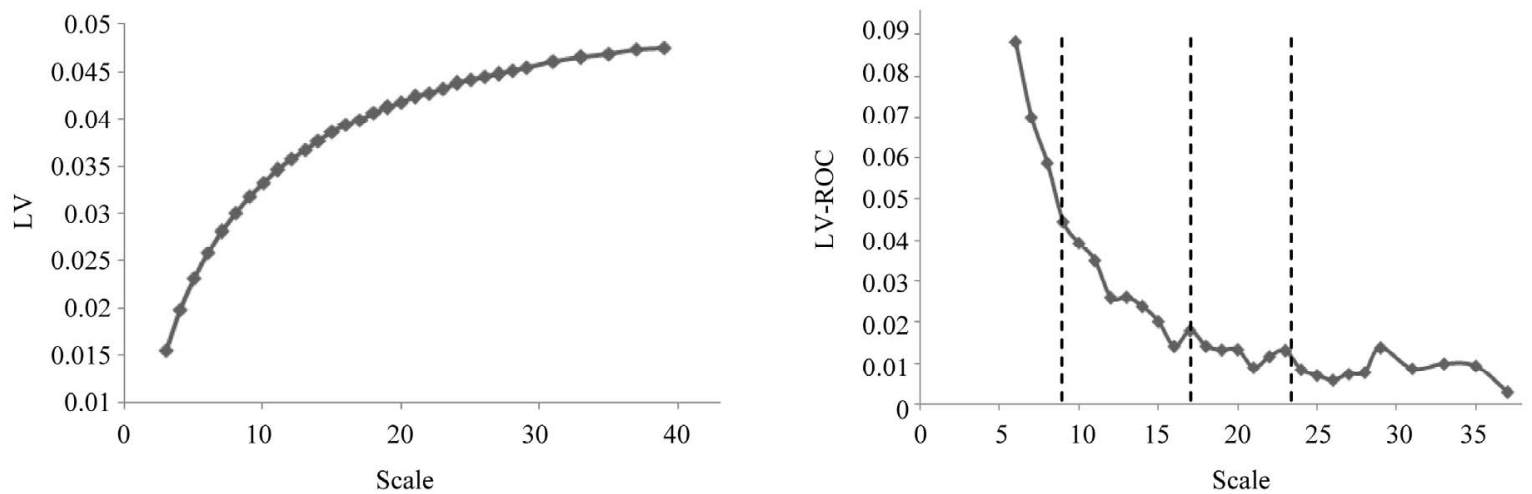

(b)
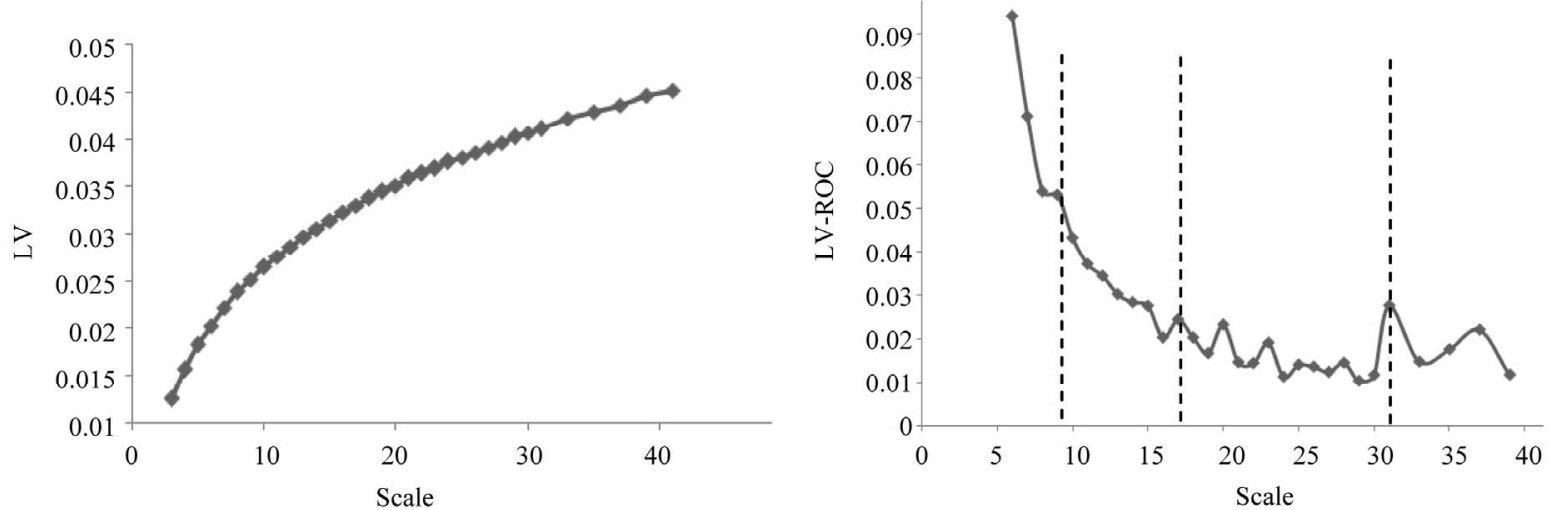

(c)

Figure 2. LV and LV-ROC Graphs of the three experiment areas. (a) LV and LV-ROC graphs of Suide; (b) LV and LV-ROC graphs of Ganquan; (c) LV and LV-ROC graphs of Yijun.

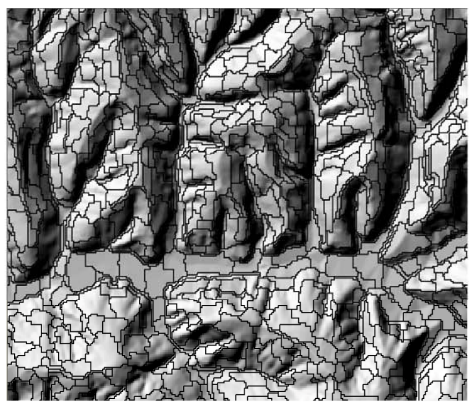

(a)

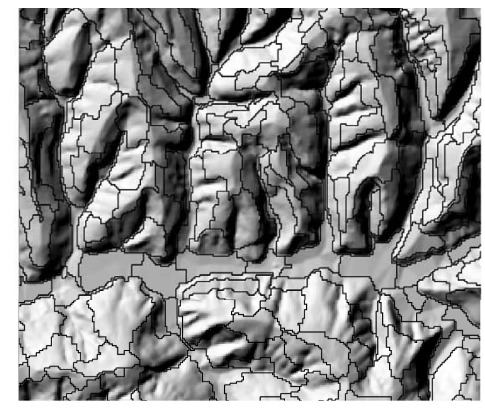

(b)

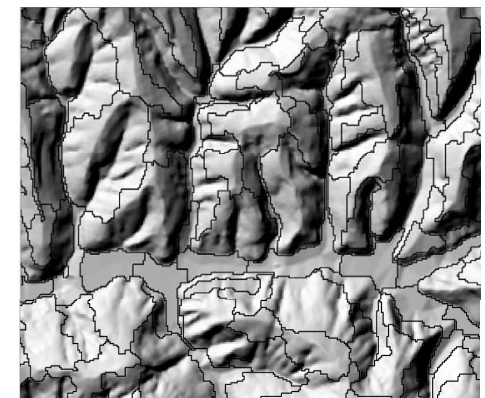

(c)

(A) 


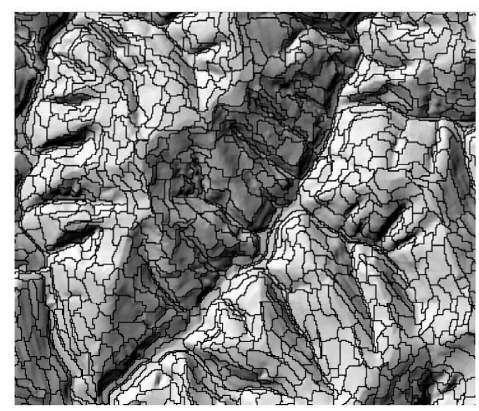

(a)

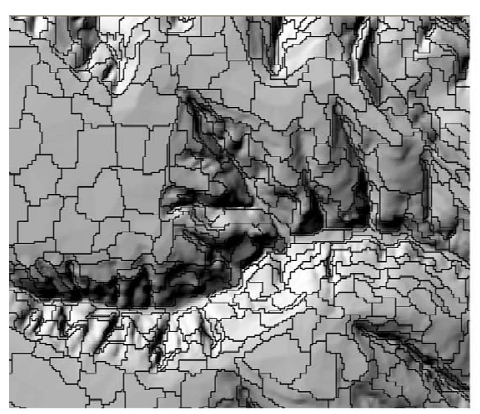

(a)

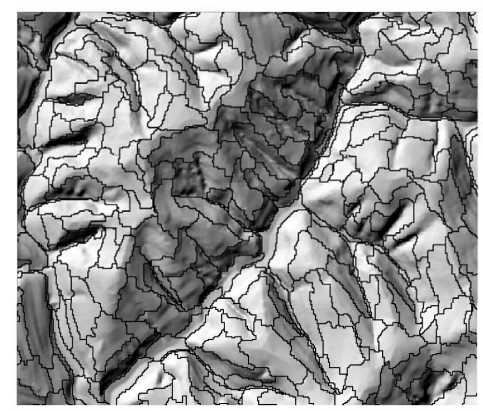

(b)

(B)

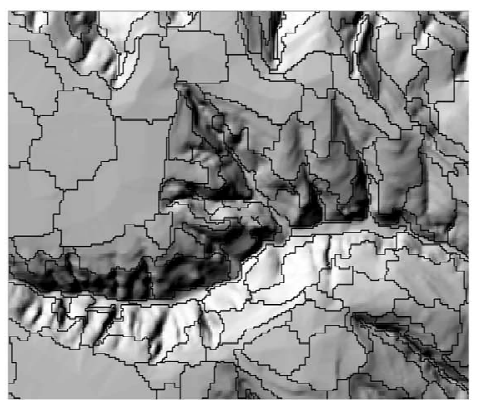

(b)

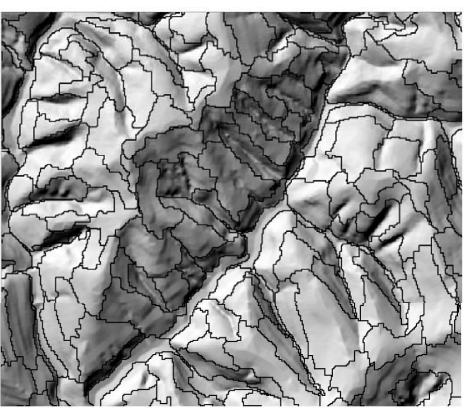

(c)

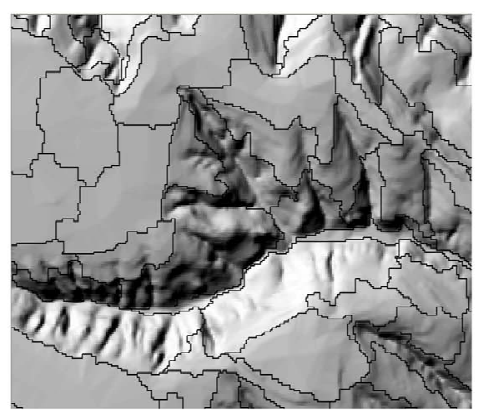

(c)

(C)

Figure 3. Segmentation results of the three experiment areas under different scales. (A) Segmentation results of Jiuyuangou under scale 4,090,110; (B) Segmentation results of Ganquan under scale 45,105,115; (C) Segmentation results of Yijun under scale $45,105,155$.

However, in this paper, slopes of different types don't have obvious boundary. So it is not appropriate to calculate the local variance based on segmentation results. The study firstly infused the three images into a synthetical one as the original layer to calculate the LV and ROCLV instead. The segmentation results of the three test areas with different landform characters showed that this changed method is efficient for multiscale slope segmentation. Furthermore, the method may also afford a new idea for traditional digital image process, especially for the multi-band image analysis.

\section{Acknowledgement}

Thanks for financially support from the National Natural Science Foundation of China (No. 40930531, No. 4080 1148, No. 41171299).

\section{REFERENCES}

[1] Z. H. Zhang, "Regional Geologic and Physiognomy Characteristic as Well as Contemporary Erosion Process of Loess Plateau," Acta Geologic Sinica, Vol. 55, No. 4, 1981, pp. 308-319.

[2] W. N. Chen, "Statistical Analysis of Gepmorphic Conditions Effection Loess Erosion in Loess Ridge-Hill Gully Region," Scientia Geographical Sinica, Vol. 8, No. 4, 1998, pp. 323-329.
[3] Q. Li, Z. C. Lu and B. Y. Yuan, "Quantitative Study Of the Stage of Geomorphological Evolution," Acta Geographica Sinica, Vol. 45, No. 1, 1990, pp. 110-120.

[4] X. Z. Ma, Z. C. Lu and D. S. Jin, "Evolution and Pissipative Structure in the Drainage-Geomorphic System," Acta Geographica Sinica, Vol. 48, No. 4, 1993, pp. 367-376.

[5] D. S. Jin, "Experiment and Simulation in Geomophology," Earthquake Press, Beijin, 1995.

[6] L. P. Zhang and Z. Z. Ma, "The Research on the Relation between Gully Density and Cutting Depth in Different Drainage Landform Evolution Periods," Geographical Research, Vol. 17, No. 3, 1998, pp. 273-278.

[7] X. N. Xiao, L. Z. Cui, C. Wang, et al., "Analysis of Spatial Data for Simulating the Development Process of Topographic Feature of Watershed," Scientia Geographical Sinica, Vol. 24, No. 4, 2004, pp. 439-443.

[8] G. A. Tang, F. Y. Li, X. J. Liu, et al., "Research on the Slope Spectrum of the Loess Plateau," Science in China Series E: Technological Sciences, Vol. 51, Supp. 1, 2008, pp. 175-185. doi:10.1007/s11431-008-5002-9

[9] Y. Zhou, G. A. Tang, X. Yang, et al., "Positive and Negative Terrains on Northern Shaanxi Loess Plateau," Journal of Geographical Sciences, Vol. 20, No. 1, 2010, pp. 64 76. doi:10.1007/s11442-010-0064-6

[10] W. N. Chen, "Statistical Analysis of Gepmorphic Conditions Effection Loess Erosion in Loess Ridge-Hill Gully Region," Scientia Geographical Sinica, Vol. 8, No. 4, 1998, pp. 323-329. 
[11] F. Y. Li, "DEM and Image Based Loess Slope Segmentation," 3rd International Congress on Image and Signal Processing, Yantai, 16-18 October 2010, pp. 2534-2538. doi:10.1109/CISP.2010.5646918

[12] E. H. Hammond, "Analysis of Properties in Landform Geo-Graphy: An Application to Broadscale Landform Mapping," Annals of the Association of American Geographers, Vol. 54, 1964, pp. 11-19.

[13] R. Dikau, E. E. Brabb and R. M. Mark, "Landform Classification of New Mexico by Computer," US Geological Survey, US Department of the Interior, Open-File Report, 1991.

[14] P. T. Giles and S. E. Franklin, "An Automated AppRoach to the Classification of the Slope Units Using Digital Data," Geomorphology, Vol. 21, No. 3, 1998, pp. 251-264. doi:10.1016/S0169-555X(97)00064-0

[15] L. Dragut and T. Blaschke, "Automated Classification of Landform Elements Using Object-Based Image Analysis," Geomorphology, Vol. 81, 2006, pp. 330-344. doi:10.1016/j.geomorph.2006.04.013

[16] P. M. Atkinson and P. J. Curran, "Defining an Optimal Size of Support for Remote Sensing Investigations," IEEE Transactions on Geoscience and Remote Sensing, Vol. 33, No. 3, 1995, pp. 768-776. doi:10.1109/36.387592

[17] C. Woodcock and A. Strahler, "The Factor of Scale in Remote Sensing," Remote Sensing of Environment, Vol. 21, No. 3, 1987, pp. 311-332. doi:10.1016/0034-4257(87)90015-0

[18] H. Yu, S.-Q. Zhang and B. Kong, "Optimal Segmentation Scale for Object-Oriented Remote Sensing Image Classification," Journal of Image and Graphics, Vol. 15, No. 2, 2010, pp. 352-360.

[19] D. Marceau and G. Hay, "Remote Sensing Contributions to the Scale Issue," Canadian Journal of Remote Sensing, Vol. 25, No. 4, 1999, pp. 357-366.

[20] T. S. Roger, S. Georges and L. Jean, "Using Color, Texture, and Hierarchical Segmentation for High-Resolution Remote Sensing," ISPRS Journal of Photogrammetric \& Remote Sensing, Vol. 63, No. 2, 2008, pp. 156-168. doi:10.1016/j.isprsjprs.2007.08.005

[21] J. L. Silvan-Cardenas, L. Wang and F. B. Zhan, "Representing Geographical Objects with Scale-Induced IndeterMinate Boundaries: A Neural Network-Based Data Model," International Journal of Geographical Information Science, Vol. 23, No. 3, 2009, pp. 295-318.

\section{doi:10.1080/13658810801932021}

[22] C. E. Woodcock, A. H. Strahler and D. L. B. Jupp, "The Use of Variograms in Remote Sensing II: Real Digital Images," Remote Sensing of Environment, Vol. 25, No. 5, 1988, pp. 349-379. doi:10.1016/0034-4257(88)90109-5

[23] J. Schiewe, L. Tufte and M. Ehlers, "Potential and Problems of Multi-Scale Segmentation Methods in Remote Sensing," Zeitschrift fur Geoinformationssysteme, Vol. 6, No. 6, 2001, pp. 34-39.

[24] P. Aplin, "On Scales and Dynamics in Observing the Environment," International Journal of Remote Sensing, Vol. 27, No. 11, 2006, pp. 2123-2140. doi: $10.1080 / 01431160500396477$

[25] P. Fisher, "The Pixel: A Snare and a Delusion," International Journal of Remote Sensing, Vol. 18, No. 15, 1997, pp. 679-685. doi:10.1080/014311697219015

[26] T. Blaschke and J. Strobl, "What's Wrong with Pixels? Some Recent Developments Interfacing Remote Sensing and GIS," Zeitschrift fur Geoinformationssysteme, Vol. 14, No. 6, 2001, pp. 12-17.

[27] G. Smith, et al., "UK Land Cover Map Production through the Generalisation of OS MasterMap(R)," Cartographic Journal, Vol. 44, No. 3, 2007, pp. 276-283. doi:10.1179/000870407X241827

[28] T. Blaschke, S. Lang and G. Hay, "Object-Based Image Analysis: Spatial Concepts for Knowledge-Driven Remote Sensing Applications," Springer-Verlag, Berlin, 2008.

[29] G. Meinel and M. Neubert, “A Comparison of Segmentation Programs for High Resolution Remote Sensing Data," Proceedings of 20th ISPRS Congress, Istanbul, 2004.

[30] L. Drăguţ, D. Tiede and S. R. Levick, "ESP: A Tool to Estimate Scale Parameter for Multiresolution Image Segmentation of Remotely Sensed Data," International Journal of Geographical Information Science, Vol. 24, No. 6, 2010, pp. 859-871. doi:10.1080/13658810903174803

[31] C. E. Woodcock, A. H. Strahler and D. L. B. Jupp, “The Use of Variograms in Remote Sensing I: Scene Models and Simulated Images," Remote Sensing of Environment, Vol. 25, No. 20, 1998, pp. 323-348.

[32] M. Kim and T. Warner, "Estimation of Optimal Image Object Size for the Segmentation Stands with Multispectral IKONOS Imagery," In: T. Blaschke, S. Lang and G. J. Hay, Eds., Object-Based Image Analysis-Spatial Concepts for Knowledge Driven Remote Sensing Application, Springer, Berlin, 2008, pp. 291-307. 